\title{
ENSEÑANZA Y PERSPECTIVAS DEL DISEÑO EN EL ECUADOR
}

\author{
Arq. Lenin Oña V.
}


Hace nueve años, por estas mismas fechas, se realizó en Quito el I Seminario Nacional de Diseño. Lo habíamos organizado en la Facultad de Artes de la Universidad Central como respuesta a una necesidad emergente tanto para el país como para la propia institución: la necesidad de determinar el papel que el diseño contemporáneo habría de jugar en nuestra sociedad y en la formación académica de la juventud ecuatoriana. Se lo hizo con retraso, como casi siempre sucede en el país en todo lo que atañe a los problemas principales de su desarrollo. Pero, en fin, se lo hizo.

Al año siguiente -1980- se reunió en esta ciudad de Cuenca el II Seminario sobre la materia. En esa oportunidad la organización corrió a cargo del Centro Interamericano de Artesanías y Artes Populares (CIDAP). Y, de nuevo, ahora, los problemas del Diseño, por tercera ocasión, son discutidos en la capital azuaya, convertida en uno de los ejes fundamentales de la investigación y la creación intelectual y artística del Ecuador. Ha sido la Pontificia Universidad Católica de Cuenca, a través de su Escuela de Diseño, la encargada de rescatar la iniciativa que estaba por perderse al cabo de tantos años de espera.

Si bien es cierto que las instituciones afines en sus cometidos con la cuestión, y en particular la universidad que debió organizar hace ya largos años el seminario que correspondía, han omitido el oportuno tratamiento de los innúmeros asuntos que implica el diseño, no se puede dejar de recordar que entidades como el Colegio de Arquitectos de Pichincha y la Universidad Laica Vicente Rocafuerte de Guayaquil reunieron, en su orden, simposios específicos, en años anteriores, sobre el diseño de interiores y sobre el uso del bambú en la construcción, la mueblería y la decoración. Temas estos, si se quiere, más cercanos a la arquitectura que al diseño propiamente tal, pero, de todos modos próximos y, por lo mismo, demostrativos de que el interés nacional por los problemas que involucra la amplia temática que nos ha vuelto a reunir no decae. 
En el período, largo período en que no se han realizado los seminarios iniciados en Quito y proseguidos en dos ocasiones en Cuenca, se ha producido un pequeño "boom" en el campo del diseño, al menos en lo que toca a la enseñanza. Han surgido cuatro institutos de nivel superior en otras tantas ciudades ecuatorianas: en la capital, en Guayaquil, en Ibarra y en Cuenca. Precisamente gracias a la iniciativa de la Escuela de Diseño de la Pontificia Universidad Católica, Sede en Cuenca, se ha rescatado el Seminario Nacional de Diseño.

En esta ocasión el tema general del simposio versa sobre $E l$ Diseño como Profesión en el Ecuador. Para comprender la evolución de los enfoques y los intereses que se han concitado en los distintos seminarios, lo que equivale a entender siquiera parcialmente la evolución del pensamiento alrededor del diseño y el desarrollo mismo de éste como actividad y preocupación intelectual en nuestro país, vale la pena referirse a los temarios de los eventos anteriores.

En el I Seminario se trataron cuatro temas, a saber: El Problema y la Función del Diseño en el Mundo Contemporáneo, La Preservación del Arte Popular y las Artesanías y su Proyección en el Diseño, El Diseño en el Arte Gráfico, Las Posibilidades del Diseño Industrial en el Ecuador.

El II Seminario adoptó un tema general: El Diseño en una Sociedad en Cambio. Trató sobre los siguientes subtemas: Diseño y Cambio Social, Creatividad y Diseño, Tecnología y Diseño, El Diseño: $\mathrm{Su}$ Arte y su Ciencia, Las Ciencias y las Artes en el Diseño: el Diseño como Profesión, Papel del Diseño en la Política Cultural del Ecuador.

Ahora, los temas específicos que se abordan tratan de El Diseño como Profesión en el Ecuador y la Formación Académica del Diseñador.

Esta enumeración de los temas enfocados en los tres seminarios de una u otra forma revelan que de lo teórico se ha avanzado hacia lo práctico; que se ha partido del debate de lo general para ir a lo concreto. Es decir que, en apariencia, se ha procedido metódica y planificadamente. Sin embargo, bien sabemos que, en verdad, este proceso sólo se ha desenvuelto de acuerdo a dichos términos ideales en lo que toca a la reflexión teórica, pues los mecanismos ineludibles de la economía no 
esperan la resolución intelectual de los problemas en los que, día a día, se involucra el diseño en todas sus manifestaciones.

Antes de trazar algunos apuntes sobre la realidad académica del diseño en el país y sobre su proyección profesional, creo que es justo mencionar por sus nombres a todas aquellas personas que intervinieron como ponentes, comentaristas, presidentes de comisiones y relatores en el I y II Seminario de Diseño. Sea éste un homenaje de reconocimiento a ellos, que aportaron como pioneros del pensamiento en la implantación del diseño como actividad profesional y artística fundamental en el desarrollo del Ecuador contemporáneo.

Los del I Seminario fueron: Edmundo Ribadeneira, Oswaldo Moreno, Manuel Mejía, Oswaldo Viteri, Leonardo Tejada, Mauricio Bueno, Hugo Hernán Hidalgo, Jorge di Paula, Diego Iturralde, Juan Fernando Pérez, Sonia Casares, Julio Romoleroux, Sonia Guevara, Nicanor Fabara, Vladimiro Silva, Mario Solís Recalde y los delegados institucionales del CIDAP y el Ministerio de Industrias.

Los del II Seminario fueron: Gerardo Martínez Espinosa, Claudio Malo González, Juan Cordero Iñiguez, Juan Martínez Borrero, Luis Molinari, Patricio Muñoz, Estuardo Cisneros, Patricio León, Eduardo Vega, Ornar Arroyo, Honorato Carvallo, Manuel Álvarez, Hernán Rodríguez Castelo, Efraín Jara, Dora Beatriz Canelos, Jorge Dávila y los representantes del Ministerio de Industrias.

Junto a todos ellos debemos recordar la participación de numerosos profesionales -arquitectos, sociólogos, antropólogos, historiadores- y estudiantes que acudieron a una o a las dos citas, y dieron su aporte en la dilucidación de una problemática que cada vez se sitúa como una de las más complejas y urgentes para un país que trata de salir desesperadamente del subdesarrollo en condiciones especialmente desventajosas, como todos los del Tercer Mundo, en una etapa histórica confusa y crítica, dramática y decisiva.

El primer punto que destaca en la situación actual es la presencia de cuatro escuelas especializadas en el nivel universitario. Pero, ¿es ello indicio de una gran demanda real de diseñadores, acorde a los requerimientos del desarrollo del país? No es así. Una investigación, por 
superficial que fuese, de la realidad ocupacional demuestra que todavía el mercado ocupacional para los diseñadores no es todo lo amplio que debería ser. Y, en consecuencia, por paradójico que luzca, una opción socorrida ha sido la académica. Dicho de otro modo, los diseñadores titulados -forzosamente todos ellos en instituciones del exterior- han encontrado su plaza de trabajo en la docencia. Desde luego, en el mejor de los casos, la combinan con la actividad profesional. Pero no deja de ser significativo que contándose apenas con unos pocos diseñadores titulados, teóricamente insuficientes para la demanda potencial que tiene el país, y como resultado de la escasa presencia de ellos en el mercado profesional real, hayan tenido que acudir a la enseñanza como medio alternativo de ocupación.

No decimos con esto que no sea necesaria, más aún imprescindible, la actividad académica para el desarrollo del diseño. Sólo hacemos hincapié en la dramática situación universitaria nacional: cada año lanzamos a la desocupación o a la semiocupación a una cantidad de diplomados que en otras circunstancias no serían suficientes para atender las exigencias que se plantean en todos los campos. Sería pecar de optimismo aseverar que el diseño va a escapar a esta realidad. Y es doblemente penoso que el panorama se presente en tales términos porque resulta evidente que la economía, que el desarrollo del Ecuador, requieren con urgencia de la intervención de los diseñadores. No es del caso ponderar el ahorro de recursos de todo tipo que se alcanza cuando se consigue un diseño óptimo. Pero si debemos todos interrogarnos y reclamar por la circunstancia anómala que vivimos: de una parte clamamos por vencer nuestras limitaciones tecnológicas y la dependencia económica que nos agobia y, de otra, poco hacemos para emplear con eficiencia los instrumentos que la tecnología y el diseño industrial nos ofrecen para solucionar tales falencias.

Consideramos de singular importancia señalar la necesidad de planificar la enseñanza del diseño atendiendo a las posibilidades reales y potenciales de demanda ocupacional. Ello implica una política nacional que prevea el aprovechamiento de los recursos materiales, técnicos, económicos y profesionales, encaminado a solucionar los requerimientos en el campo que nos ocupa. Sin embargo, han de ser los propios diseñadores quienes han de difundir la necesidad del diseño por medios más eficientes que los que hasta ahora se han utilizado. Deben impulsar 
la toma de conciencia generalizada sobre la importancia que tiene su actividad como medio insustituible para satisfacer las aspiraciones de mejoramiento del estándar de vida de los más amplios sectores de la población.

A la vista de los planes de estudio de las instituciones que nos los han remitido -la de Cuenca, Quito y Guayaquil- es posible intentar un breve análisis de la realidad académica actual.

1. Ante todo se observa que las escuelas de Quito y Cuenca preparan profesionales específicamente dedicados al diseño, mientras que la de Guayaquil lo hace, más bien, en el campo de la decoración de interiores.

2. Sin embargo, hay diferencias entre los perfiles de las dos primeras escuelas. La de Quito prepara por separado diseñadores industriales y gráficos, mientras que la de Cuenca otorga un título general en diseño gráfico y de objetos.

3. Así mismo varía la duración de las carreras: cinco ciclos semestrales en la de Quito; diez ciclos, cuya duración no se estipula, en la de Cuenca; y cuatro años de estudio en la de Guayaquil.

4. No existe unidad entre los planes y programas. Lo cual es obvio para la escuela de la Universidad Vicente Rocafuerte de Guayaquil, y explicable en todos los casos por las disparejas circunstancias de surgimiento y desarrollo de las distintas escuelas.

5. Sólo en la Escuela Metropolitana de Quito, de preferencia los profesores son diseñadores titulados. En todos los casos se anota la presencia de numerosos arquitectos en las cátedras.

Todos estos factores inducen a reflexionar no sólo en la falta de coordinación que impera en la enseñanza superior del país con todas las carreras, sino, además, en cuán indispensable sería subsanar esta situación en lo que toca al diseño.

¿Cuáles son las perspectivas del diseño en el Ecuador? Sin penetrar en la teorización amplia de las circunstancias que han de 
favorecerlo, y que de hecho pasan por amplios y profundos cambios en la estructura económico-social de la sociedad ecuatoriana, consideramos que se pueden emprender una serie de acciones concretas:

1. Publicitar a través de los medios de comunicación la trascendencia del diseño. Una campaña prolongada de este tipo demanda la producción de materiales literarios y visuales accesibles, demostrativos y ejemplificadores para el público.

2. Requerir, hasta conseguirlo, que las instituciones y organismos estatales que tienen que recurrir al diseño, pero que hasta ahora no lo ponen en manos de diseñadores profesionales, reemplacen a los diseñadores más o menos empíricos por los profesionalmente formados.

3. Mantener con el apoyo y financiamiento público y privado concursos periódicos de diseño de objetos de amplia utilización y consumo.

4. Constituir, o al menos poner las bases constitutivas de un colegio profesional de diseñadores, que ha de cumplir las tareas inherentes a la defensa y perfeccionamiento gremiales.

5. Realizar campañas puntuales en la pequeña y en la gran industria para demostrar prácticamente las ventajas y bondades del diseño nacional.

6. Realizar periódicamente seminarios de diseño como el que se iniciara hace nueve años y que hasta ahora sólo se ha reunido en tres ocasiones.

7. Realizar seminarios especializados en uno u otro campo del diseño; así mismo, conferencias, mesas redondas y publicaciones.

8. Ahondar en el estudio del diseño artesanal ecuatoriano, cuyas fuentes estéticas y funcionales han de estar en la raíz del diseño contemporáneo que necesitamos, para resolver los grandes problemas sociales que éste trata de enfrentar en el país. 
No quisiera concluir estas notas sin llamar la atención sobre el imperativo social y económico que constituye la implantación del diseño industrial como herramienta en el mejoramiento de la calidad de la vida. Y lo voy a hacer con la cita del artículo La Democracia de las Cosas, de reciente data, aparecido en el diario El País, de Madrid. Dice su autor, Eduardo Haro Tecglen: "Bellísimas ciudades antiguas son una maldición para sus habitantes. Los viajeros que se embriagan en sus calles delgadas con el aroma a especias y a cuero, con el zumbido de las abejas y el golpe seco del artesano en el cobre no saben lo que es vivir desde siempre en esa miseria pegajosa, en esa interminable Edad Media. Si entre los viajeros hay algún filósofo -seguro que lo habrá- describirá, sin duda, la relación perfecta entre el hombre y su hábitat, entre el trabajo y la subsistencia, y dirá que se trata de una medida humana. Es mentira. Es filosofía de turista".

Añade el ensayista: "Esa manera de pensar se está trasladando a nuestra vida cotidiana en forma de añoranza aristocrática sobre el palacio que se substituye, y se alza ante una democracia de las cosas que pretenden un cierto disfrute de los más de aquello que antes era para los menos".

Concluye así el pensador periodístico: "Sin embargo, el ensueño de la calidad se ha apoderado de nosotros. Querríamos el concierto y el cuadro, y no sus reproducciones mecánicas; el alto, jugoso y tierno solomillo; la casa ajardinada y la playa solitaria. Sólo entonces que no escucharíamos ni miraríamos; no comeríamos, no iríamos a la playa. Todo eso sería para otros. Como antes. Probablemente ya no va a haber en Europa revoluciones de los pobres. Pero las revoluciones de las colonias". 
